\title{
Synergistic Activity of Berberine with Azithromycin against Pseudomonas Aeruginosa Isolated from Patients with Cystic Fibrosis of Lung In Vitro and In Vivo
}

\author{
YongTao Lia JianRong Huang ${ }^{\mathrm{a}}$ LanJuan Lia LinSheng Liu ${ }^{\mathrm{b}}$ \\ aState Key Laboratory for Diagnosis and Treatment of Infectious Diseases, The First Affiliated Hospital, \\ College of Medicine, Zhejiang University, Hangzhou, bepartment of Respiration, Sanshui District \\ People's Hospital, Foshan, China
}

\section{Key Words}

Berberine • Azithromycin • Pseudomonas aeruginosa • Cystic fibrosis • Biofilm

\begin{abstract}
Background/Aims: Pseudomonas aeruginosa (PA) is one of the major opportunistic pathogens which can cause chronic lung infection of cystic fibrosis (CF). The formation of PA biofilm promotes CF development and restricts the antimicrobial efficacies of current antibiotics. Methods: The antimicrobial effects of azithromycin (AZM) and berberine (BER) alone and in combination were evaluated using microdilution method, checkerboard assay, time-kill test, qRT-PCR analysis and absorption method. The treatments of AZM and/or BER were further evaluated in an animal lung infection model via observing survival rate, bacterial burden and histopathology of lung, the levels of pro-/anti-inflammatory cytokines. Results: AZM-BER were demonstrated to be synergistic against ten clinical PA isolates as well as the standard reference PA ATCC27853, in which PA03 was the most susceptible isolate to AZM-BER with FICI of 0.13 and chosen for subsequent experiments. The synergism of AZM-BER was further confirmed against PA03 in time-kill test and scanning electron microscope (SEM) at their concentrations showing synergism. In PA03, we found that AZM-BER could significantly attenuate productions of a series of virulence factors including alginate, LasA protease, LasB protease, pyoverdin, pyocyanin, chitinase as well as extracellular DNA, and remarkably inhibit the levels of quorum sensing (QS) molecules and the expressions of lasl, las $R, r h l l, r h l R$ at $1 / 2 \times \mathrm{MIC}, 1 \times \mathrm{MIC}$ and $2 \times$ MIC. In the infection model, the mice survival were increased markedly, the inflammations of infected lungs were improved greatly along with reduced IL- 6 , IL-8 and ascended IL-10 at $0.8 \mathrm{mg} / \mathrm{kg}$ of AZM combined with $3.2 \mathrm{mg} / \mathrm{kg}$ of BER. Conclusion: BER might be a promising synergist to enhance the antimicrobial activity of $A Z M$ in vitro and in vivo.
\end{abstract}




\section{Introduction}

Pseudomonas aeruginosa (PA) is a versatile opportunistic pathogen and can trigger a wide range of life-threatening nosocomial infections including cystic fibrosis (CF). CF is a familiar chronic airway infection and characterized by accumulation of purulent and viscous mucus, obstruction, airway destruction as well as fibrosis with incidence of 1 in 2,500 live births [1-8]. The susceptibility of lung to PA-induced CF infection can be attributed to the well adaptation of PA to the inflammatory response to the respiratory and conductive zone of lung, whereas the most important adaptive strategy of PA is biofilm formation [9-11]. Biofilm is a complicated three-dimensional structure consisting of surface-attached microbial cells and self-produced extracellular substance encasing the cells. Biofilm phenotype renders high resistance of enclosed cells to antimicrobial agents that can be up to 10-1000 fold greater than that of its planktonic counterpart $[12,13]$. The formation of PA biofilm results in futilities of many antibiotics and treatment failures.

Current widely-employed approach to enhancing antibacterial activities of traditional antibiotics is the use of drug combination [14-16]. Azithromycin (AZM), one of the macrolide antibiotics, has been demonstrated to possess bacteriostatic and antibiofilm activities against PA at therapeutic concentrations. Increasing evidence showed that AZM improved survival rate in PA biofilm-induced CF patients [17-19]. However, the incidence of resistance to AZM rises remarkably in especially the newly-isolated clinical PA isolates. Since it can disorganize biofilm structure and reverse biofilm cells to planktonic state in PA, AZM in combination with a drug which also owns anti-Pseudomonas activity might be more effective than AZM used alone in the treatment of PA biofilm-associated CF infections [15].

Mounting reports have revealed that active ingredients from medicinal plants were promising for antimicrobial purposes [20-25]. Berberine (BER), a natural isoquinoline alkaloid found in a variety of medicinal plants, had a broad antimicrobial spectrum alone or in combination with other antibiotics [26-28]. The present study aimed to investigate the antibacterial potentials and associated mechanisms of BER and AZM alone and in combination against clinical PA isolates from CF patients. The treatment efficacies of BER and/or AZM were further evaluated in a mice lung infection model.

\section{Materials and Methods}

\section{Bacterial strains}

Ten clinical isolates of PA isolated from CF patients were provided by the First Affiliated Hospital of Zhejiang University (Hangzhou, Zhejiang, China). The standard strain of PA ATCC27853 was obtained from the National Institute for the Control of Pharmaceutical and Biological Products (NICPBP, Beijing, China). All strains were stored at $-80^{\circ} \mathrm{C}$ and sub-cultivated in Luria-Bertani (LB, Hope, Qingdao, China) medium at $37^{\circ} \mathrm{C}$ $220 \mathrm{rpm}$ for $18 \mathrm{~h}$ till the strains reached to the late log phase. Chromobacterium violaceum CV026 (NICPBP, Beijing, China) was cultured in LB medium supplemented with N-hexanoyl homoserine lactone (HHL, $10 \mu \mathrm{M}$, Fluka, Buchs, Switzerland) to induce violacein. The bacterial suspension was incubated aerobically at $37^{\circ} \mathrm{C}$ for $16-18 \mathrm{~h}$ with gentle shaking till $\mathrm{OD}_{600}$ reached to 0.1 prior to experiments.

\section{Susceptibility testing}

The anti-Pseudomonas activities of AZM and BER were conducted using broth microdilution method in strict accordance with the criteria of the Clinical and Laboratory Standards Institute (CLSI). The bacterial suspension $\left(5 \times 10^{5} \mathrm{CFU} / \mathrm{mL}\right)$ was incubated with AZM or BER in a 96-well microtitre plate for $24 \mathrm{~h}$ at $37^{\circ} \mathrm{C}$. The antimicrobial agents were serially two-fold diluted with final concentrations ranging $2-1024 \mu \mathrm{g} / \mathrm{mL}$ for AZM and 64-2048 $\mu \mathrm{g} / \mathrm{mL}$ for BER. The minimum inhibitory concentration (MIC) was defined as the lowest concentration of AZM or BER to cause no visual growth of bacteria. The combined interaction of AZM with BER was assessed by checkerboard assay. The final concentrations of the drugs were prepared in a range of 1/64-16 × MIC for AZM and 1/64-1 × MIC for BER. The fractional inhibitory concentration index (FICI) was equal to (MIC of AZM in combination/MIC of AZM alone) + (MIC of BER in combination/MIC of BER alone). 


\section{Cellular Physiology Cell Physiol Biochem 2017;42:1657-1669

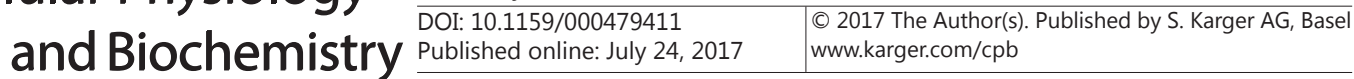

Li et al.: BER and AZM Against PA

The definitions of synergism, indifference and antagonism were interpreted as FICI $\leq 0.5,>0.5$ and $\leq 4.0$, and $>4.0$, respectively [29].

Time-kill (T-K) assay

The antimicrobial efficacies of AZM and/or BER was further surveyed in PA03 due to its lowest FICI. PA03 suspension ( $\left.5 \times 10^{5} \mathrm{CFU} / \mathrm{mL}\right)$ was initially incubated with AZM and/or BER at their concentrations showing synergism as determined previously by the checkerboard assay. At the designated time points $(0$, 4, 8, 12 and $24 \mathrm{~h}$ ), an aliquot of suspension was pipetted and smeared to count the viable cells on LB agar plate. The control contained bacteria only. The T-K curves were plotted by logarithm of colony forming unit (CFU) per milliliter versus time (h). Synergism was defined as an increase of $\geq 2 \log _{10} \mathrm{CFU} / \mathrm{mL}$ in killing for the combined agents compared with the most active agent used alone. Antagonism was defined as a decrease of $\geq 2 \log _{10} \mathrm{CFU} / \mathrm{mL}$ in killing for the combined agents compared with the most active agent alone. Indifference was defined as a decrease of $\leq 2 \log _{10} \mathrm{CFU} / \mathrm{mL}$ in killing for the combined agents compared with any agents used [25].

\section{Inhibition of preformed PA biofilm}

PA03 ( $\left.5 \times 10^{5} \mathrm{CFU} / \mathrm{mL}\right)$ biofilm was formed in $\mathrm{LB}$ medium for $24 \mathrm{~h}$ at $37^{\circ} \mathrm{C}$, and then incubated with AZM and BER alone and in combination at $1 / 2 \times$ MIC, $1 \times$ MIC and $2 \times$ MIC in a 96-well flat-bottomed microtitre plate for another 24,48 and $72 \mathrm{~h}$ at $37^{\circ} \mathrm{C}$. The medium free of agent was set as control. The biofilm formation $(\%)$ were measured by crystal violet (CV) staining, which was equal to $\mathrm{OD}_{545}$ of sample treated / $\mathrm{OD}_{545}$ of control [30].

\section{Scanning electron microscope}

The PA03 biofilms were treated with or without 1/16×MIC AZM and 1/16×MIC BER alone and in combination for $24 \mathrm{~h}$ as described above on sterile cover slips in a 6-well plate. After treatments, the cover slips were rinsed by sterile PBS for three times, and then fixed by $2.5 \%$ (v/v) glutaraldehyde overnight. After drying, the samples were dehydrated by increasing concentrations of ethanol $(20 \%, 40 \%, 70 \%, 90 \%, 95 \%$ and $100 \%, v / v, 2$ min each). Finally, the samples were processed by gold sputtering (JEOL JFC 1200E Ion sputtering device) and observed by SEM (JSM-6700F, Japan).

\section{Quantification of biofilm protein}

The procedures of PA03 biofilm protein extraction were described previously with a few modifications [31]. Briefly, the preformed PA03 biofilms were incubated with or without AZM and BER alone and in combination at $1 / 2 \times \mathrm{MIC}, 1 \times \mathrm{MIC}$ and $2 \times \mathrm{MIC}$ at $37^{\circ} \mathrm{C}$ for $24 \mathrm{~h}$. After incubations, the biofilms were washed gently by sterile PBS to remove planktonic cells and adhered loosely cells. The biofilm cells were then scratched into a test tube, boiled in $5 \mathrm{~mL} 15 \mathrm{mM} \mathrm{NaOH}$ for $30 \mathrm{~min}$, and centrifuged at 10,000 g for $5 \mathrm{~min}$. The concentrations of collected protein were measured following instructions of a BCA Protein Quantification Kit (Vazyma, Nanjing, Jiangsu, China).

\section{Evaluations of virulence factors}

(i) Alginate. The alginates of PA03 biofilms were extracted and quantified as described previously with minor modifications [31]. Briefly, the preformed PA03 biofilms treated as above were scratched and washed by sterile PBS for several times. The suspension was centrifuged at $10000 \mathrm{~g}$ for $20 \mathrm{~min}$ at $4^{\circ} \mathrm{C}$. Then the pellets were added with $10 \mathrm{mM}$ EDTA, vortexed for $15 \mathrm{~min}$ and centrifuged at $10000 \mathrm{~g}$ for $20 \mathrm{~min}$ at $4^{\circ} \mathrm{C}$. The collected supernatant was then incubated with 2.5 volume of cold ethanol $(100 \%, \mathrm{v} / \mathrm{v})$ at $-20^{\circ} \mathrm{C}$ for $1 \mathrm{~h}$ and centrifuged at $10000 \mathrm{~g}$ for $20 \mathrm{~min}$ at $4^{\circ} \mathrm{C}$. After being dissolved in sterile PBS, the deposit containing alginate was analyzed by phenol-sulphuric acid method [16].

(ii) Protease. The lasA staphylolytic activities of preformed PA03 biofilms treated as above were measured according to the procedures as described previously with minor modifications [32]. Briefly, the stored Staphylococcus aureus cells were cultured for $18 \mathrm{~h}$, centrifuged at $12000 \mathrm{~g}$ for $15 \mathrm{~min}$, and resuspended in $\mathrm{pH}$ 8.5 0.02 M Tris- $\mathrm{HCl}$ to the final concentration of $1 \times 10^{6} \mathrm{CFU} / \mathrm{mL}$. The suspension was boiled for 10 min and diluted with $\mathrm{pH} 8.50 .02 \mathrm{M}$ Tris- $\mathrm{HCl}$ to $\mathrm{OD}_{595}$ of 0.8 . After coincubation with cell-free supernatant of PA03 (1:9), the absorbance of the diluted suspension was measured at $595 \mathrm{~nm}$.

(iii) Elastase. The LasB elastolytic activities of preformed PA03 biofilms treated as described above 
were determined using Elastin-Congo red (ECR; Sigma, St. Louis, USA) as substrate [33]. Briefly, the culture supernatant $(100 \mu \mathrm{L})$ of PA03 was incubated with $900 \mu \mathrm{L}$ of ECR buffer $(20 \mathrm{mg}$ ECR, $100 \mathrm{mM}$ Tris, $1 \mathrm{mM}$ $\mathrm{CaCl}_{2}, \mathrm{pH} 7.5$ ) at $37^{\circ} \mathrm{C}$ for $3 \mathrm{~h}$. Then the suspension was mixed with $1 \mathrm{~mL}$ of pH $6.00 .7 \mathrm{M}$ sodium phosphate buffer and centrifuged at $12000 \mathrm{~g}$ for $15 \mathrm{~min}$ to remove insoluble ECR. The absorbance was finally measured at $495 \mathrm{~nm}$.

(iv) Pyoverdin. The secreted pyoverdins of preformed PA03 biofilms treated as above were detected according to the methods described previously with modest adjustments [34]. Briefly, the cell-free culture supernatant of PA03 was obtained by centrifuging at $12000 \mathrm{~g}$ for $15 \mathrm{~min}$. The relative pyoverdin content was measured by a fluorescence spectrophotometer (F-700, Hitachi, Japan) at $405 \mathrm{~nm}$ excitation and 465 nm emission.

(v) Pyocyanin. The pyocyanins of preformed PA03 biofilms following the same treatments as above were quantified based on the procedures described previously with a few adjustments [35]. Briefly, the cellfree culture supernatant of PA03 $(5 \mathrm{~mL})$ was mixed with $3 \mathrm{~mL}$ of chloroform and $1 \mathrm{~mL}$ of $5 \mathrm{mM} \mathrm{HCl}$ in order to extract pyocyanin. The absorbance was finally measured at $520 \mathrm{~nm}$.

(vi) Chitinase. The chitinase activities of preformed PA03 biofilms with the same treatments as above were evaluated based on the previous procedures [36]. Briefly, the culture supernatant (200 $\mu \mathrm{L})$ of PA03 was co-incubated with carboxymethyl-chitin-remazol brilliant violet $(100 \mu \mathrm{L}, 2 \mathrm{mg} / \mathrm{mL}$, Loewe Biochemica, Sauerlach, Germany) and sodium acetate buffer $(100 \mu \mathrm{L}, 0.05 \mathrm{M}, \mathrm{pH} 5.0)$ for $20 \min$ in a $50^{\circ} \mathrm{C}$ water bath. The suspension was mixed with $\mathrm{HCl}(100 \mu \mathrm{L}, 2 \mathrm{M})$ for $10 \mathrm{~min}$ in an ice bath and centrifuged at $10000 \mathrm{~g}$ for $5 \mathrm{~min}$. The absorbance was finally measured at $540 \mathrm{~nm}$.

(vii) Extracellular DNA (eDNA). The eDNA contents of preformed PA03 biofilms were determined after the parallel treatments as above according to the procedures as described previously [37]. Briefly, PA03 suspension was centrifuged at $12000 \mathrm{~g}$ for $5 \mathrm{~min}$. The supernatant was collected to precipitate eDNA by adding $\mathrm{NaCl}(250 \mathrm{mM})$ and ethanol (2:1), and then re-suspended in $100 \mu \mathrm{L}$ of TE buffer (10 mM Tris$\mathrm{HCl}, \mathrm{pH}$ 8.0; $1 \mathrm{mM}$ EDTA, $\mathrm{pH}$ 8.0). The concentrations of eDNA were measured by dsDNA quantification kit according to the manufacturer's instruction (Quant-iT ${ }^{\mathrm{TM}}$, PicoGreen dsDNA Assay Kit, Life technologies). Briefly, the extracted eDNA $(100 \mu \mathrm{L})$ was incubated with PicoGreen reagent $(100 \mu \mathrm{L})$ for $5 \mathrm{~min}$ at $25^{\circ} \mathrm{C}$. The fluorescence intensity was measured at $480 \mathrm{~nm}$ excitation and $520 \mathrm{~nm}$ emission (TEKAN, Infinite M200 Pro, Switzerland).

\section{Violacein quantification}

The violacein contents were measured to reveal the inhibitory activities of PA quorum sensing (QS) molecules following the procedures as described previously with minor modifications [38]. Briefly, PA03 suspension $(100 \mathrm{~mL})$ was centrifuged at $16000 \mathrm{~g}$ for $15 \mathrm{~min}$. The supernatant was then transferred to a clean flask, added with an equivalent volume of ethyl acetate and centrifuged at $16000 \mathrm{~g}$ for $15 \mathrm{~min}$. The organic phase was pooled and concentrated by rotary evaporation for further use. CV026 suspension $\left(1 \mathrm{~mL}, \mathrm{OD}_{600}=\right.$ 0.1 ) was incubated with extracted QS molecules $(1 \mathrm{mg} / \mathrm{mL})$ for $24 \mathrm{~h}$ at $37^{\circ} \mathrm{C}$ with gentle shaking. Following incubation, a volume of bacterial broth $(200 \mu \mathrm{L})$ was transferred to Eppendorf tube and mixed with $10 \%$ (w/v) SDS $(200 \mu \mathrm{L}$ ) for $5 \mathrm{~min}$. Subsequently, $900 \mu \mathrm{L}$ of water-saturated butanol was added into the bacterial broth, vortexed vigorously for $20 \mathrm{~s}$, and centrifuged at $16000 \mathrm{~g}$ for $15 \mathrm{~min}$. Finally, the violacein-containing butanol phase were transferred to a new flat-bottomed microplate for absorbance measurement at $585 \mathrm{~nm}$.

\section{Expressions of QS-related genes}

The total RNA was extracted using MagExtractor-RNA kit (ToyoBo, Tokyo, Japan). Complementary DNA was prepared by ReverTra Ace qPCR RT Master Mix with gDNA Remover kit (ToyoBo, Tokyo, Japan). The primer sequences of lasI, lasR, rhlI, rhlR and ropD were synthesized by Sangon Biotech (Shanghai, China; Table 2). The qRT-PCR was performed on ABI7000 fluorescent quantitative PCR system (Applied Biosystem) followed by $95^{\circ} \mathrm{C}$ for $60 \mathrm{~s}$, and $95^{\circ} \mathrm{C}$ for $15 \mathrm{~s}, 56^{\circ} \mathrm{C}$ for $15 \mathrm{~s}, 72^{\circ} \mathrm{C}$ for $45 \mathrm{~s}$ for 40 cycles. All data were normalized to the reference gene ropD. The relative expressions of target-gene were calculated as a fold change of $2^{-\Delta \Delta \mathrm{Ct}}$ value, in which $\Delta \Delta \mathrm{Ct}=\Delta \mathrm{C}_{\mathrm{t}}^{\text {target gene }}-\Delta \mathrm{C}_{\mathrm{t}}^{\text {ropD }}$ as described previously [39].

\section{Animal experiment}

All animal experimental procedures were conducted in conformity with institutional guidelines for the care and use of laboratory animals of The First Affiliated Hospital, College of Medicine, Zhejiang University 
and the National Institutes of Health Guide for Care and Use of Laboratory Animals. Forty pathogen-free BALB/c mice (6-8 weeks and 18-22g) were purchased from Center of Experimental Animals, Zhejiang University, Hangzhou, China. These mice were divided into five groups: normal group, infection control group, AZM-treated group, BER-treated group, and AZM+BER-treated group. The mice were maintained in micro-isolator cages in a pathogen-free barrier facility throughout the experiment, being provided with food and water ad libitum for 10 days to acclimatize the environment. An experimental model of chronic lung infection was established as described previously with minor modifications [29]. Briefly, the neutropenia of mice was induced by intraperitoneal injection of cyclophosphamide (Sigma-Aldrich, MO, USA) 4 days prior to PA infection (150 mg/kg), 1 day before PA infection (100 mg/kg), and 1 day postinfection of PA (100 mg/ $\mathrm{kg}$ ). Each mouse was challenged intranasally with $40 \mu \mathrm{L} 1 \times 10^{7} \mathrm{CFU} / \mathrm{mL}$ PA03 for $24 \mathrm{~h}$. After that, the mice were treated with (i) no drug, (ii) $0.8 \mathrm{mg} / \mathrm{kg}$ AZM, (iii) $3.2 \mathrm{mg} / \mathrm{kg} \mathrm{BER}$, and (iv) $0.8 \mathrm{mg} / \mathrm{kg} \mathrm{AZM}+3.2 \mathrm{mg}$ / $\mathrm{kg}$ BER via tail vein. Animals were sacrificed on day 3 . The lungs were excised aseptically and homogenized in sterile PBS. The homogenized suspensions were spread on LB agar plates at $35^{\circ} \mathrm{C}$ for $48 \mathrm{~h}$ of incubation.

\section{Histopathology}

The en bloc excised lung tissues were fixed in $10 \%$ formalin for $24 \mathrm{~h}$ at $4^{\circ} \mathrm{C}$, dehydrated in an ethanol gradient (30-100\%), and embedded in paraffin. The longitudinal sections (5 mm thick) were stained with hematoxylin and eosin (HE).

\section{Cytokine estimation}

After homogenization and centrifugation, the lung suspension was used to estimate the levels of IL-6, IL-8 and IL-10 by a commercial enzyme-linked immunosorbent assay kits (PeprotechInc., Rocky Hill, NJ, USA) as per manufacturer's instructions.

\section{Statistical analysis}

Each experiment was performed triplicate in three different occasions. The data of experimental result were recorded as mean \pm standard deviation and calculated by SPSS 19.0 (SPSS Inc., Chicago, IL, USA). The survival analysis was processed by Kaplan-Meier test via Log-rank method. Differences between groups were determined using analysis of variance (ANOVA). Statistical significance was defined when a $p$-value was less than 0.05 .

\section{Results}

Antimicrobial activities of AZM and/or BER against $P A$

As shown, BER was synergistic with AZM against the tested PA isolates (n = 11) with a FICI range of 0.13-0.5. The MICs of AZM and BER in combination decreased by $4-16$ and $>4$ fold compared with their MICs used alone (Table 1). Evidently, PA03 was the most susceptible among the tested isolates due to its lowest FICI and chosen for subsequent experiments. In T-K test, AZM $(16 \mu \mathrm{g} / \mathrm{mL}$ or $1 / 16 \times$ MIC) and BER (64 $\mu \mathrm{g} / \mathrm{mL}$ or $1 / 16 \times \mathrm{MIC}$ ) alone
Table 1. Susceptibility of AZM and BER alone and in combination against planktonic $P$. aeruginosa isolates

\begin{tabular}{|c|c|c|c|}
\hline strains & $\begin{array}{l}\text { MIC }_{\text {AZM }} / \mathrm{MIC}_{\mathrm{BER}} \\
\text { (alone, } \mu \mathrm{g} / \mathrm{mL} \text { ) }\end{array}$ & $\begin{array}{c}\mathrm{MIC}_{\mathrm{AZM}} / \mathrm{MIC}_{\mathrm{BER}} \\
\text { (in combination, } \mu \mathrm{g} / \mathrm{mL} \text { ) }\end{array}$ & FICI (Int) \\
\hline PA ATCC27853 & $8 />1024$ & $2 / 256$ & $0.50(\mathrm{~S})$ \\
\hline PA01 & $256 />1024$ & $32 / 128$ & $0.25(\mathrm{~S})$ \\
\hline PA02 & 512 / >1024 & $32 / 256$ & $0.31(\mathrm{~S})$ \\
\hline PA03 & $256 />1024$ & $16 / 64$ & $0.13(\mathrm{~S})$ \\
\hline PA04 & $128 />1024$ & $16 / 128$ & $0.25(\mathrm{~S})$ \\
\hline PA05 & $256 />1024$ & $64 / 128$ & $0.38(\mathrm{~S})$ \\
\hline PA06 & $256 />1024$ & $64 / 128$ & $0.38(\mathrm{~S})$ \\
\hline PA07 & $512 />1024$ & $32 / 256$ & $0.31(\mathrm{~S})$ \\
\hline PA08 & $256 />1024$ & $32 / 256$ & $0.38(\mathrm{~S})$ \\
\hline PA09 & $512 />1024$ & $64 / 128$ & $0.25(\mathrm{~S})$ \\
\hline PA10 & $512 />1024$ & $64 / 128$ & $0.25(S)$ \\
\hline
\end{tabular}

Table 2. Primers for PCR

\begin{tabular}{lll}
\hline Primer & Forward sequence (5'-3') & Reverse sequence (5'-3') \\
\hline lasl & CGCACATCTGGGAACTCA & CGGCACGGATCATCATCT \\
lasR & CTGTGGATGCTCAAGGACTAC & AACTGGTCTTGCCGATGG \\
rhlI & GTAGCGGGTTGGGGATG & CGGCATCAGGTCTTCATCG \\
rhlR & GCCAGCGTCTTGTTCGG & CGGTCTGCCTGAGCCATC \\
ropD & CGAACTGCTTGCCGACTT & GCGAGAGCCTCAAGGATAC \\
\hline
\end{tabular}






Fig. 1. (A) Time-Kill curves of PA03 cells post-treatments with or without $16 \mu \mathrm{g} / \mathrm{mL}$ AZM $(1 / 16 \times$ MIC) and $64 \mu \mathrm{g} / \mathrm{mL} \mathrm{BER}(1 / 16 \times \mathrm{MIC})$ alone and in combination for $24 \mathrm{~h}$ at $37^{\circ} \mathrm{C}$. (B) The established biofilm formation (\%) of PA03 measured by crystal violet staining at $545 \mathrm{~nm}$ post-treatments with or without AZM and BER alone and in combination at $1 / 2 \times \mathrm{MIC}, 1 \times \mathrm{MIC}$ and $2 \times \mathrm{MIC}$ for 24,48 and $72 \mathrm{~h}$ at $37^{\circ} \mathrm{C}$. (C) Representative images of PA03 biofilm using scanning electron microscope post-treatments with or without $1 / 16 \times$ MIC AZM and $1 / 16 \times$ MIC BER alone and in combination for $24 \mathrm{~h}$ at $37^{\circ} \mathrm{C}$. The initial inoculum was $5 \times 10^{5} \mathrm{CFU} /$ mL. ${ }^{*}, p<0.05$; $^{* *}, p<0.01 ;{ }^{* * *}, p<0.001$; compared with the control.

could not inhibit the growth of PA03 within $24 \mathrm{~h}$, while the bacterial growth decreased after $4 \mathrm{~h}$ of co-incubation with AZM and BER. Following $24 \mathrm{~h}$ of treatment, AZM and BER together reduced the pathogen above $2 \log _{10} \mathrm{CFU} / \mathrm{mL}$ compared with AZM (the most active agent) alone (Fig. 1A). The antibiofilm potentials of AZM and/or BER at $1 / 2 \times$ MIC, $1 \times$ MIC and $2 \times$ MIC were inspected in 24-, 48- and 72-h preformed PA03 biofilms. As demonstrated, the 24-h preformed PA03 biofilms were inhibited at $1 / 2 \times, 1 \times, 2 \times$ MIC of AZM and $2 \times$ MIC of BER $(p<$ $0.05, p<0.01, p<0.01, p<0.05)$, but disrupted at the combined concentrations of $1 / 2 \times$ MIC, $1 \times$ MIC and $2 \times$ MIC $(p<0.001, p<0.001, p<0.001)$. The antibacterial effects of AZM and/ or BER in 48-h preformed biofilms were similar to those in 24-h preformed biofilms. As for 72 -h preformed biofilms, AZM alone at $2 \times$ MIC $(p<0.05)$ and AZM-BER at $1 / 2 \times$ MIC, $1 \times$ MIC and $2 \times$ MIC $(p<0.05, p<0.001, p<0.001)$ were found effectively to suppress the formations of PA03 biofilms (Fig. 1B). In SEM, AZM $(1 / 16 \times$ MIC) or BER $(1 / 16 \times$ MIC) began to disorganize the PA03 biofilms, but amounts of biofilm cells could be observed compared with the control. The biofilm matrixes were almost removed and the biofilm cells were decreased markedly when AZM and BER were used concomitantly compared with the drug-free control (Fig. 1C).

\section{Effects of AZM and/or BER on virulence factors in PA03}

Virulence factors of PA played a critical role in the regulation of biofilm formation and pathogenic invasion. In this study, a group of virulence factors including biofilm protein, alginate, LasA, LasB, pyodervin, pyocyanin, chitinase and eDNA were investigated at AZM and BER alone and in combination of $1 / 2 \times$ MIC, $1 \times$ MIC, $2 \times$ MIC. As shown, the productions of biofilm protein and alginate were inhibited by AZM alone $(p<0.05, p<0.01, p<0.01)$ and $1 \times$ MIC, $2 \times$ MIC BER $(p<0.05, p<0.05)$, while AZM-BER exhibited better inhibitions than 
Fig. 2. Evaluations of (A) biofilm protein (\%) by a BCA Protein Quantification Kit, (B) alginate (\%) by phenol-sulphuric acid method, (C) LasA staphylolytic activity (\%) by absorbance at 595 $\mathrm{nm}$, (D) LasB elastolytic activity (\%) by absorbance at $495 \mathrm{~nm}$, (E) pyoverdin (\%) by fluorescence intensity at $405 \mathrm{~nm}$ excitation and $465 \mathrm{~nm}$ emission, (F) pyocyanin (\%) by absorbance at $520 \mathrm{~nm}$, (G) chitinase activity (\%) by absorbance at $540 \mathrm{~nm}$, and (H) eDNA (\%) by fluorescence intensity at $480 \mathrm{~nm}$ excitation and $520 \mathrm{~nm}$ emission in PA03 biofilm after treatments with or without AZM and BER alone and in combination at $1 / 2 \times$ MIC, $1 \times$ MIC and $2 \times$ MIC at $37{ }^{\circ} \mathrm{C}$ for $24 \mathrm{~h}$. The initial inoculum was $5 \times 10^{5} \mathrm{CFU} / \mathrm{mL}$. * $p<$ 0.05 ; **, $p<0.01$; ***, $p<0.001$; compared with the control.
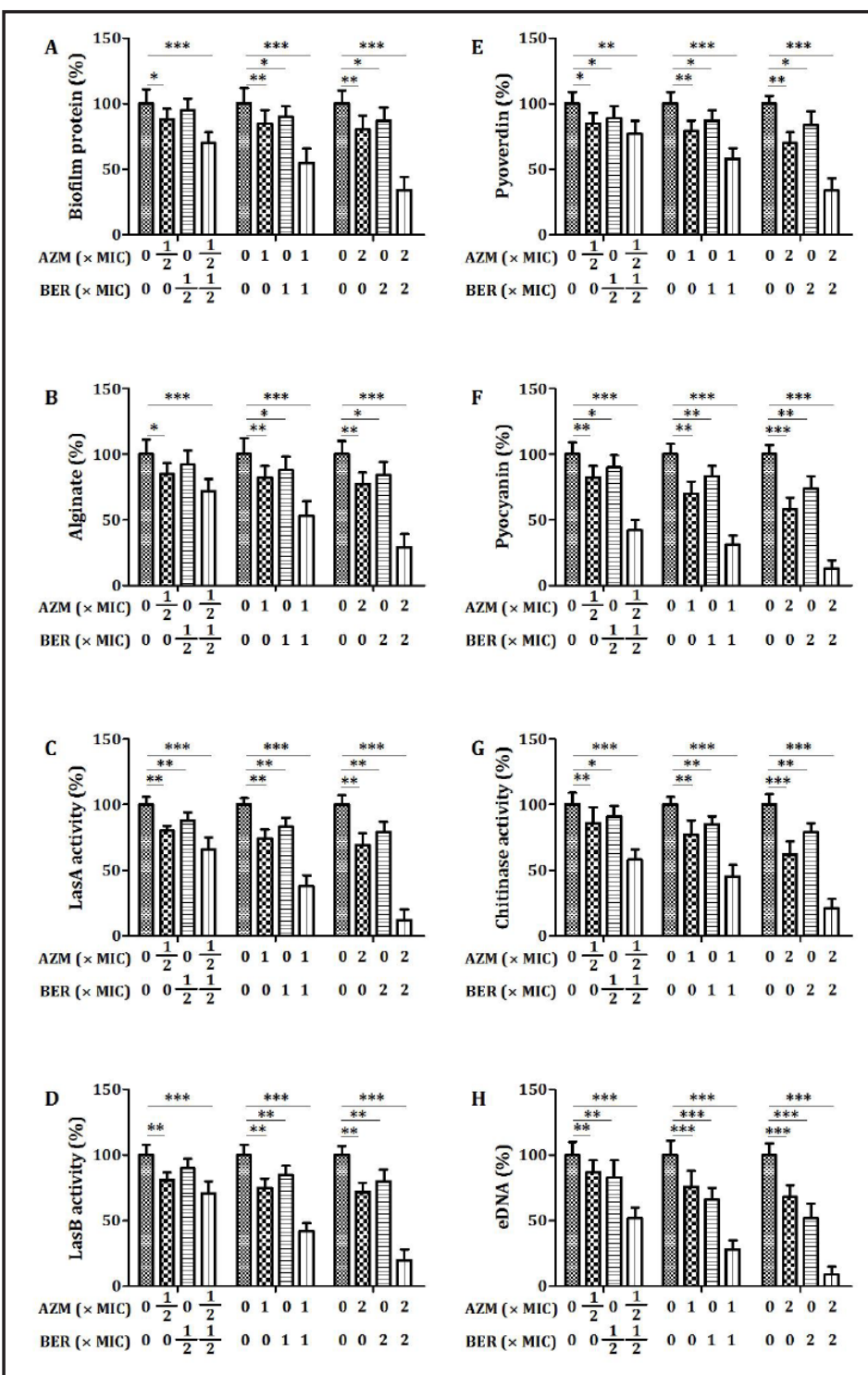

either drug used alone ( $p<0.001$, Fig. 2A and 2B). The LasA activities decreased evidently after the administrations of AZM and BER alone and in combination $(p<0.01, p<0.001$, Fig. 2C). Except $1 / 2 \times$ MIC BER, the LasB activity declined in a similar manner with LasA (Fig. 2D). The pyodervin content remained approximately $85 \%, 79 \%, 70 \%$ after the treatments of AZM ( $p<0.05, p<0.01, p<0.01), 89 \%, 87 \%, 84 \%$ after the exposures to BER $(p<0.05$, $p<0.05, p<0.05)$, and 77\%, 58\%, 34\% when AZM-BER were used $(p<0.01, p<0.001, p<$ 0.001 , Fig. 2E) compared with the control. It was obvious that AZM-BER resulted in 58\%, $69 \%, 87 \%$ of decreases for pyocyanin ( $p<0.001, p<0.001, p<0.001$, Fig. $2 \mathrm{~F}$ ), $42 \%, 55 \%$, $79 \%$ of reductions for chitinase ( $p<0.001, p<0.001, p<0.001$, Fig. $2 \mathrm{G}$ ), and $48 \%, 72 \%, 91 \%$ of declines for eDNA ( $p<0.001, p<0.001, p<0.001$, Fig. $2 \mathrm{H}$ ) compared with the control.

Effects of AZM and/or BER on the generations of QS molecules and the expressions of QSrelated genes

CV026 could produce violacein in the presence of QS molecules secreted by PA. Guided by this principle, the levels of QS molecules were monitored. As exhibited, the violacein levels decreased significantly at AZM and BER alone and in combination of $1 / 2 \times$ MIC, $1 \times$ MIC and $2 \times$ MIC $(p<0.01$ or $p<0.001$, Fig. $3 \mathrm{~A})$ except $1 / 2 \times$ MIC BER. Meanwhile, the expressions of lasI, lasR, rhlI and $r h l R$ related with two well-described QS systems in PA were analyzed by 
Fig. 3. Analyses of (A) violacein (\%) to detect the quorum sensing (QS) molecules by absorbance at $585 \mathrm{~nm}$, and relative expressions of (B) lasI, (C) lasR, (D) rhll, and (E) $r h l R$ by qRT-PCR by $2^{-\Delta \Delta \mathrm{Ct}}$ method, in which ropD was set as the reference control in PA03 biofilm after treatments with or without AZM and BER alone and in combination at $1 / 2 \times \mathrm{MIC}$, $1 \times \mathrm{MIC}$ and $2 \times \mathrm{MIC}$ at $37{ }^{\circ} \mathrm{C}$ for $24 \mathrm{~h}$. The initial inoculum was $5 \times 10^{5}$ CFU/mL. *, $p<0.05$; **, $p<0.01$; ***, $p$ $<0.001$; compared with the control.
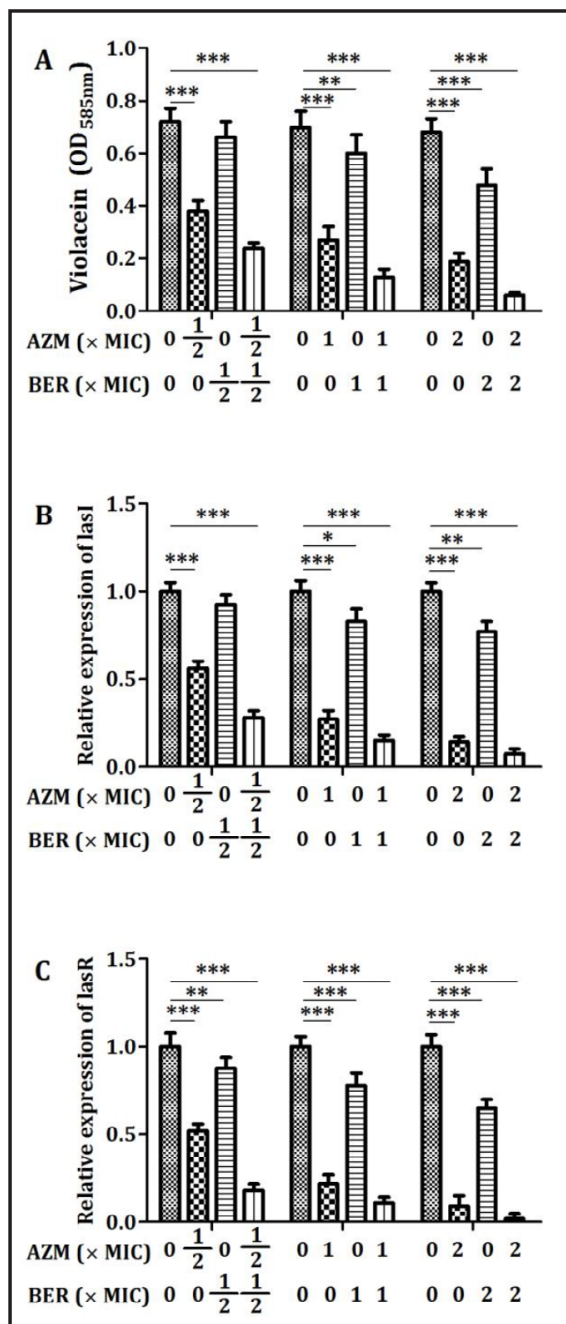
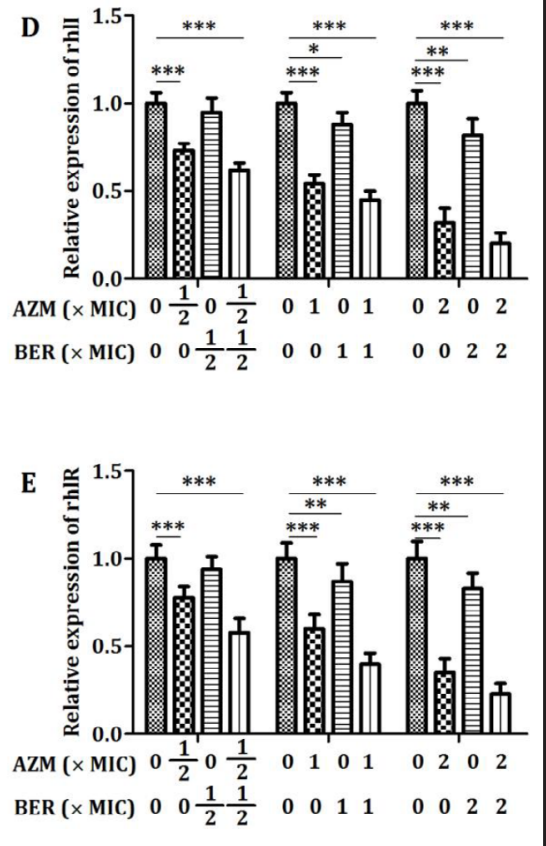

qRT-PCR. The results showed that the expressions of lasI, rhlI, rhlR experienced 1.21-14.28, 1.14-5, 1.15-4.35 fold of decrease after drug treatments at the chosen concentrations except $1 / 2 \times$ MIC BER ( $p<0.05$ or $p<0.01$ or $p<0.001$, Fig. 3B, D, E) compared with the control. We also noticed that the expressions of lasR were down-regulated by 1.14-50 fold at all agent concentrations studied ( $p<0.01$ or $p<0.001$, Fig. 3C) compared with the control. These results suggested that AZM-BER presented more effective inhibitions against the levels of QS molecules and the expressions of QS-related genes in PA03 compared with AZM or BER alone.

Treatments of AZM and/or BER in a rat lung infection model

At the $8^{\text {th }}$ day post-infection, $0,2,1$ and 7 mice survived $(n=8)$ with the treatments of no drug, $0.8 \mathrm{mg} / \mathrm{kg}$ AZM, $3.2 \mathrm{mg} / \mathrm{kg}$ BER and $0.8 \mathrm{mg} / \mathrm{kg}$ AZM plus $3.2 \mathrm{mg} / \mathrm{kg}$ BER (Fig. $4 \mathrm{~A})$. At the $3^{\text {rd }}$ day post-infection, the bacterial burdens of lung were significantly relieved by AZM and BER alone and in combination compared with the drug-free control $(p<0.001, p<$ $0.001, p<0.001$, Fig. 4B). In control group, no affected areas and abnormal morphology were observed. The lung tissues showed macro-abscesses and notable hemorrhage with minor normal areas. The histological analyses revealed pneumonic consolidation and infiltrated neutrophils in excised tissues. These results suggested severe inflammation in mice lungs post-infection (Fig. 4C). The solo use of AZM or BER mitigated the lung inflammation with shrunk abscesses, reduced hemorrhagic areas, and decreased levels of pro-inflammatory cytokines IL-6, IL-8 ( $p<0.05$ or $p<0.001$, Fig. 4C and Fig. 5). The AZM-BER further alleviated 

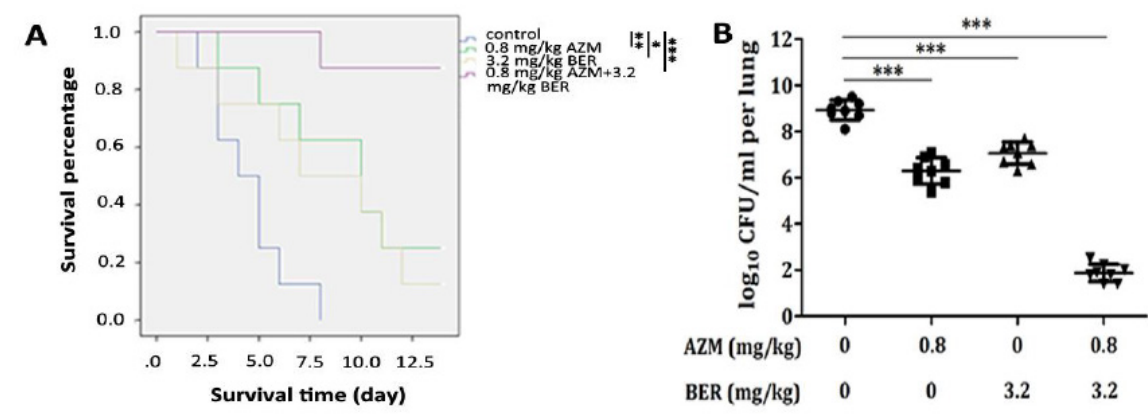

C Normal control Infection control

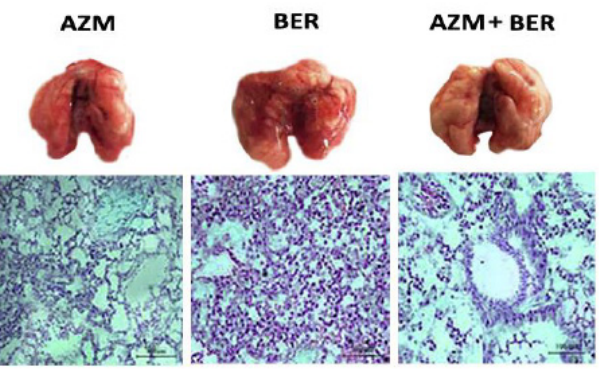

Fig. 4. A mice lung infection model ( $\mathrm{n}=8$ per each group) was established for evaluating the synergistic effects of AZM and BER alone and in combination. (A) The survival percentage was calculated by counting mice dying each day. (B) The bacterial burden was determined in whole lung homogenates from the sacrificed mice by counting colony forming unit (CFU) per lung. (C) Representative digital photographs and pathological sections by HE staining of lungs. The mice were treated with no drug, $0.8 \mathrm{mg} / \mathrm{kg} \mathrm{AZM,} 3.2 \mathrm{mg} /$ $\mathrm{kg}$ BER, and $0.8 \mathrm{mg} / \mathrm{kg} \mathrm{AZM}+3.2 \mathrm{mg} / \mathrm{kg}$ BER. The drugs were injected via tail vein post-infection of 3 days. The initial inoculum was $1 \times 10^{7} \mathrm{CFU} / \mathrm{mL} .{ }^{*}, p<0.05 ;{ }^{* *}, p<0.01$; ${ }^{* *}, p<0.001$; compared with the control.
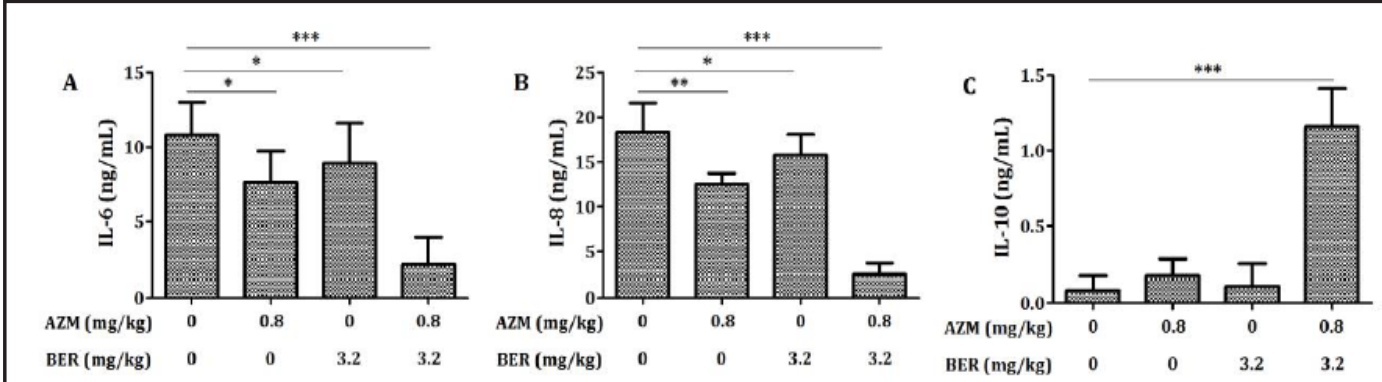

Fig. 5. The pro-inflammatory cytokine levels of (A) IL-6, (B) IL-8 and the anti-inflammatory cytokine level of (C) IL-10 were determined by a commercial enzyme-linked immunosorbent assay kits in whole lung homogenates from the sacrificed mice. The experimental conditions could be seen in Fig. 4. *, $p<0.05$; ${ }^{* *}, p<$ $0.01{ }^{* * *}, p<0.001$; compared with the control.

abscesses and hemorrhage, weakened the inflammation in infected lungs by declining the levels of pro-inflammatory cytokines IL-6, IL-8 and increasing the level of anti-inflammatory cytokine IL-10 ( $p<0.001$, Fig. 4C and Fig. 5).

\section{Discussion}

Biofilm formation and consequent emergence of multidrug resistance limit the antipseudomonal efficacies of current antibiotics available. Thus, exploiting novel agents with antimicrobial potentials against PA become urgent. Although BER has been extensively

\section{KARGER}


investigated in some bacteria such as Staphylococcus aureus (MIC $=32-256 \mu \mathrm{g} / \mathrm{mL}$ ), less studies were focused on the antipseudomonal activity of BER which was relatively weak (MIC $\geq 512 \mu \mathrm{g} / \mathrm{mL}$ ) $[25,40]$. Our experiments confirmed the poor antipseudomonal activity of BER (MIC $>1024 \mu \mathrm{g} / \mathrm{mL}$ ). As demonstrated previously, the MIC of AZM against PA altered in a wide range from 2 to $512 \mu \mathrm{g} / \mathrm{mL}$ depending on the strains and the testing procedures $[41,42]$. Herein, the MIC of AZM ranged from 128 to $512 \mu \mathrm{g} / \mathrm{mL}$ indicating the resistances of these clinical PA isolates to AZM. Our results manifested that either AZM or BER alone was hard to combat PA, but their combination displayed synergistic potential to inhibit the bacterial growth at lower concentrations.

Biofilm is a complex structure to protect the encased cells from host immune clearance and antimicrobial attacks via the secreted matrixes mainly composed of alginate. Besides alginate, several proteins and organic molecules including LasA, LasB, pyoverdin, pyocyanin, chitinase, and eDNA are also the virulence factors of PA [16]. In this study, sub-MIC of AZM and BER in combination was inhibitory on the biofilm formation and the productions of virulence factors in PA03. Actually, most virulence factors were subject to the regulation of quorum sensing (QS) system. As known, there are two QS systems found in PA, namely las and rhl systems [43]. The las system generates 30-C12-HSL molecules to interact with LasR and controls the levels of LasA, LasB, and chitinase; while rhl system produces C4HSL to conjugate with RhlR and activates the expression of pyocyanin [43, 44]. We found that QS and the expressions of QS-related genes as well as eDNA which was also essential for biofilm structure could be significantly suppressed by AZM plus BER at sub-MIC. These results suggested that the anti-PA activity of AZM-BER might be associated with attenuating virulence factors.

Several reports displayed that both AZM and BER could target efflux pumps (MexXY) $[40,45]$ and eDNA $[26,30]$ in PA. However, macrolides were supposed to be difficult of diffusion across the outer membrane of most gram-negative bacteria [46]. In addition, BER could also act on cytoplasmic membrane and intra-nuclear DNA [47-49]. It is likely that different modes of action of AZM and BER might account for the synergism of AZM-BER, which still needs more studies.

After the in vitro experiments, a mice lung infection model was established using PA03. We observed that AZM-BER remarkably reduced the lung bacterial burden and improved the survival rate compared with either AZM or BER. The same conclusion could also be inferred from the decreased levels of anti-inflammation cytokines (IL-6 and IL-8) and the increased level of pro-inflammation cytokine (IL-10). These results were consistent with the findings of other studies $[15,19]$, and demonstrated that BER was synergistic with AZM in the treatment of in vivo PA infection.

In conclusion, AZM and BER in combination could inhibit PA growths in both planktonic and biofilm states, decrease the levels of PA virulence factors, decline the expressions of PA QS-related genes, and improve the survival rate of PA-infected mice. These results suggested that BER could become a promising synergist to enhance the antimicrobial activity of AZM in vitro and in vivo. Nevertheless, more studies are needed to decipher the underlying synergistic mechanism of AZM-BER.

\section{Disclosure Statement}

None.

\section{References}

\footnotetext{
1 Folkesson A, Jelsbak L, Yang L, Johansen HK, Ciofu O, Hoiby N, Molin S: Adaptation of Pseudomonas aeruginosa to the cystic fibrosis airway: an evolutionary perspective. Nat Rev Microbiol 2012;10:841-851.
} 


\section{Cellular Physiology Cell Physiol Biochem 2017;42:1657-1669 \begin{tabular}{l|l} 
DOI: 10.1159/000479411 & $\begin{array}{l}\text { O 2017 The Author(s). Published by S. Karger AG, Basel } \\
\text { www.karger.com/cpb }\end{array}$ \\
\hline
\end{tabular}}

Li et al.: BER and AZM Against PA

2 Langan KM, Kotsimbos T, Peleg AY: Managing Pseudomonas aeruginosa respiratory infections in cystic fibrosis. Curr Opin Infect Dis 2015;28:547-556.

- Cohen TS, Prince A: Cystic fibrosis: a mucosal immunodeficiency syndrome. Nat Med 2012;18:509-519.

-4 Riethmuller J, Herrmann G, Graepler-Mainka U, Hellwig D, Heuer HE, Heyder S, Koster H, Kinder B, Kroger K, Paul K, Poplawska K, Melichar VO, Smaczny C, Mellies U: Sequential inhalational tobramycin-colistincombination in CF-patients with chronic P. aeruginosa colonization-an observational study. Cell Physiol Biochem 2016;39:1141-1151.

5 Tavakoli Tabazavareh S, Seitz A, Jernigan P, Sehl C, Keitsch S, Lang S, Kahl BC, Edwards M, Grassme H, Gulbins E, Becker KA: Lack of sphingosine causes susceptibility to pulmonary Staphylococcus aureus infections in cystic fibrosis. Cell Physiol Biochem 2016;38:2094-2102.

6 Romano FB, Tang Y, Rossi KC, Monopoli KR, Ross JL, Heuck AP: Type 3 secretion translocators spontaneously assemble a hexadecameric transmembrane complex. J Biol Chem 2016;291:6304-6315.

7 Wang L, Wu G, Qin X, Ma Q Zhou Y, Liu S, Tan Y: Expression of nodal on bronchial epithelial cells influenced by lung microbes through DNA methylation modulates the differentiation of T-helper cells. Cell Physiol Biochem 2015;37:2012-2022.

-8 Merches K, Khairnar V, Knuschke T, Shaabani N, Honke N, Duhan V, Recher M, Navarini AA, Hardt C, Haussinger D, Tummler B, Gulbins E, Futerman AH, Hoffmann D, Lang F, Lang PA, Westendorf AM, Lang KS: Virus-induced Type I interferon deteriorates control of systemic Pseudomonas aeruginosa infection. Cell Physiol Biochem 2015;36:2379-2392.

-9 Hoffmann N, Rasmussen TB, Jensen PO, Stub C, Hentzer M, Molin S, Ciofu O, Givskov M, Johansen HK, Hoiby $\mathrm{N}$ : Novel mouse model of chronic Pseudomonas aeruginosa lung infection mimicking cystic fibrosis. Infect Immun 2005;73:2504-2514.

10 Hoiby N: P. aeruginosa in cystic fibrosis patients resists host defenses, antibiotics. Microbe (ASM) 2006;1:571.

-11 Bjarnsholt T, Jensen PO, Fiandaca MJ, Pedersen J, Hansen CR, Andersen CB, Pressler T, Givskov M, Hoiby $\mathrm{N}$ : Pseudomonas aeruginosa biofilms in the respiratory tract of cystic fibrosis patients. Pediatr Pulmonol 2009;44:547-558.

12 Hoiby N, Ciofu O, Bjarnsholt T: Pseudomonas aeruginosa biofilms in cystic fibrosis. Future Microbiol 2010;5:1663-1674.

13 Mulcahy LR, Isabella VM, Lewis K: Pseudomonas aeruginosa biofilms in disease. Microb Ecol 2014;68:112.

14 Doring G, Conway SP, Heijerman HG, Hodson ME, Hoiby N, Smyth A, Touw DJ: Antibiotic therapy against Pseudomonas aeruginosa in cystic fibrosis: a European consensus. Eur Respir J 2000;16:749-767.

15 Saini H, Chhibber S, Harjai K: Azithromycin and ciprofloxacin: a possible synergistic combination against Pseudomonas aeruginosa biofilm-associated urinary tract infections. Int J Antimicrob Agents 2015;45:359-367.

16 Das MC, Sandhu P, Gupta P, Rudrapaul P, De UC, Tribedi P, Akhter Y, Bhattacharjee S: Attenuation of Pseudomonas aeruginosa biofilm formation by Vitexin: A combinatorial study with azithromycin and gentamicin. Sci Rep 2016;6:23347.

17 Gillis RJ, Iglewski BH: Azithromycin retards Pseudomonas aeruginosa biofilm formation. J Clin Microbiol 2004;42:5842-5845.

18 Hoffmann N, Lee B, Hentzer M, Rasmussen TB, Song Z, Johansen HK, Givskov M, Hoiby N: Azithromycin blocks quorum sensing and alginate polymer formation and increases the sensitivity to serum and stationary-growth-phase killing of Pseudomonas aeruginosa and attenuates chronic P. aeruginosa lung infection in Cftr(-/-) mice. Antimicrob Agents Chemother 2007;51:3677-3687.

19 Tsai WC, Hershenson MB, Zhou Y, Sajjan U: Azithromycin increases survival and reduces lung inflammation in cystic fibrosis mice. Inflamm Res 2009;58:491-501.

20 Shao J, Cheng H, Wang C, Wang Y: A phytoanticipin derivative, sodium houttuyfonate, induces in vitro synergistic effects with levofloxacin against biofilm formation by Pseudomonas aeruginosa. Molecules 2012;17:11242-11254.

21 Tang F, Li WH, Zhou X, Liu YH, Li Z, Tang YS, Kou X, Wang SD, Bao M, Qu LD, Li M, Li B: Puerarin protects against Staphylococcus aureus-induced injury of human alveolar epithelial A549 cells via downregulating alpha-hemolysin secretion. Microb Drug Resist 2014;20:357-363. 


\section{Cellular Physiology Cell Physiol Biochem 2017;42:1657-1669 \begin{tabular}{l|l} 
DOI: 10.1159/000479411 2017 & $\begin{array}{l}\text { O 2017 The Author(s). Published by S. Karger AG, Basel } \\
\text { www.karger.com/cpb }\end{array}$ \\
\hline
\end{tabular}}

Li et al.: BER and AZM Against PA

22 Cai W, Fu Y, Zhang W, Chen X, Zhao J, Song W, Li Y, Huang Y, Wu Z, Sun R, Dong C, Zhang F: Synergistic effects of baicalein with cefotaxime against Klebsiella pneumoniae through inhibiting CTX-M-1 gene expression. BMC Microbiol 2016;16:181.

23 Lee YS, Han SH, Lee SH, Kim YG, Park CB, Kang OH, Keum JH, Kim SB, Mun SH, Shin DW, Kwon DY: Synergistic effect of tetrandrine and ethidium bromide against methicillin-resistant Staphylococcus aureus (MRSA). J Toxicol Sci 2011;36:645-651.

-24 de Rapper S, Viljoen A, van Vuuren S: The in vitro antimicrobial effects of Lavandula angustifolia essential oil in combination with conventional antimicrobial agents. Evid Based Complement Alternat Med 2016;2016:2752739.

25 Jayaraman P, Sakharkar MK, Lim CS, Tang TH, Sakharkar KR: Activity and interactions of antibiotic and phytochemical combinations against Pseudomonas aeruginosa in vitro. Int J Biol Sci 2010;6:556-568.

26 Guo N, Zhao X, Li W, Shi C, Meng R, Liu Z, Yu L: The synergy of berberine chloride and totarol against Staphylococcus aureus grown in planktonic and biofilm cultures. J Med Microbiol 2015;64:891-900.

27 Dziedzic A, Wojtyczka RD, Kubina R: Inhibition of oral Streptococci growth induced by the complementary action of berberine chloride and antibacterial compounds. Molecules 2015;20:13705-13724.

-28 Budeyri Gokgoz N, Avci FG, Yoneten KK, Alaybeyoglu B, Ozkirimli E, Sayar NA, Kazan D, Sariyar Akbulut B: Response of Escherichia coli to prolonged berberine exposure. Microb Drug Resist DOI:10.1089/ mdr.2016.0063.

29 Odds F: Synergy, antagonism, and what the chequerboard puts between them. J Antimicrob Chemother 2003;52:1.

30 Gnanadhas DP, Elango M, Datey A, Chakravortty D: Chronic lung infection by Pseudomonas aeruginosa biofilm is cured by L-Methionine in combination with antibiotic therapy. Sci Rep 2015;5:16043.

-31 Tribedi P, Sil AK: Cell surface hydrophobicity: a key component in the degradation of polyethylene succinate by Pseudomonas sp. AKS2. J Appl Microbiol 2014;116:295-303.

32 Kessler E, Safrin M, Olson JC, Ohman DE: Secreted LasA of Pseudomonas aeruginosa is a staphylolytic protease. J Biol Chem 1993;268:7503-7508.

-33 Ohman DE, Cryz SJ, Iglewski BH: Isolation and characterization of Pseudomonas aeruginosa PAO mutant that produces altered elastase. J Bacteriol 1980;142:836-842.

-34 Adonizio A, Kong K-F, Mathee K: Inhibition of quorum sensing-controlled virulence factor production in Pseudomonas aeruginosa by South Florida plant extracts. Antimicrob Agents Chemother 2008;52:198-203.

-35 Essar DW, Eberly L, Hadero A, Crawford IP: Identification and characterization of genes for a second anthranilate synthase in Pseudomonas aeruginosa: interchangeability of the two anthranilate synthases and evolutionary implications. J Bacteriol 1990;172:884-900.

-36 Neiendam Nielsen M, Sorensen J: Chitinolytic activity of Pseudomonas fluorescens isolates from barley and sugar beet rhizosphere. FEMS Microbiol Ecol 1999;30:217-227.

-37 Tang L, Schramm A, Neu TR, Revsbech NP, Meyer RL: Extracellular DNA in adhesion and biofilm formation of four environmental isolates: a quantitative study. FEMS Microbiol Ecol 2013;86:394-403.

-38 Blosser RS, Gray KM: Extraction of violacein from Chromobacterium violaceum provides a new quantitative bioassay for N-acyl homoserine lactone autoinducers. J Microbiol Methods 2000;40:47-55.

-39 Livak KJ, Schmittgen TD: Analysis of relative gene expression data using real-time quantitative PCR and the 2- $\Delta \Delta \mathrm{CT}$ method. Methods 2001;25:402-408.

40 Morita Y, Nakashima K, Nishino K, Kotani K, Tomida J, Inoue M, Kawamura Y: Berberine is a novel type efflux inhibitor which attenuates the MexXY-mediated aminoglycoside resistance in Pseudomonas aeruginosa. Front Microbiol 2016;7:1223.

41 Imperi F, Leoni L, Visca P: Antivirulence activity of azithromycin in Pseudomonas aeruginosa. Front Microbiol 2014;5:178.

42 Buyck JM, Plesiat P, Traore H, Vanderbist F, Tulkens PM, Van Bambeke F: Increased susceptibility of Pseudomonas aeruginosa to macrolides and ketolides in eukaryotic cell culture media and biological fluids due to decreased expression of OprM and increased outer-membrane permeability. Clin Infect Dis 2012;55:534-542.

-43 Pesci EC, Pearson JP, Seed PC, Iglewski BH: Regulation of las and rhl quorum sensing in Pseudomonas aeruginosa. J Bacteriol 1997;179:3127-3132. 


\section{Cellular Physiology Cell Physiol Biochem 2017;42:1657-1669 \begin{tabular}{l|l|l} 
DOI: 10.1159/000479411 & $\begin{array}{l}\text { O 2017 The Author(s). Published by S. Karger AG, Basel } \\
\text { www.karger.com/cpb }\end{array}$ \\
\hline
\end{tabular}}

Li et al.: BER and AZM Against PA

44 Bratu S, Gupta J, Quale J: Expression of the las and rhl quorum-sensing systems in clinical isolates of Pseudomonas aeruginosa does not correlate with efflux pump expression or antimicrobial resistance. J Antimicrob Chemother 2006;58:1250-1253.

45 Sugimura M, Maseda H, Hanaki H, Nakae T: Macrolide antibiotic-mediated downregulation of MexAB-OprM efflux pump expression in Pseudomonas aeruginosa. Antimicrob Agents Chemother 2008;52:4141-4144.

$\$ 46$ Nikaido $\mathrm{H}$ : The role of outer membrane and efflux pumps in the resistance of gram-negative bacteria. Can we improve drug access? Drug Resist Updat 1998;1:93-98.

47 Wang X, Yao X, Zhu Z, Tang T, Dai K, Sadovskaya I, Flahaut S, Jabbouri S: Effect of berberine on Staphylococcus epidermidis biofilm formation. Int J Antimicrob Agents 2009;34:60-66.

48 Stermitz FR, Lorenz P, Tawara JN, Zenewicz LA, Lewis K: Synergy in a medicinal plant: antimicrobial action of berberine potentiated by 5 '-methoxyhydnocarpin, a multidrug pump inhibitor. Proc Natl Acad Sci USA 2000;97:1433-1437.

49 Severina, II, Muntyan MS, Lewis K, Skulachev VP: Transfer of cationic antibacterial agents berberine, palmatine, and benzalkonium through bimolecular planar phospholipid film and Staphylococcus aureus membrane. IUBMB Life 2001;52:321-324. 